\begin{tabular}{|c|c|c|}
\hline $\begin{array}{l}\text { PKS } \\
\text { PUBLIC } \\
\text { KNOLLEDGE } \\
\text { PROJECT }\end{array}$ & $\begin{array}{c}\text { REVISTA DE GEOGRAFIA } \\
\text { (RECIFE) } \\
\text { http://www.revista.ufpe.br/revistageografia }\end{array}$ & $\begin{array}{l}\text { OJS } \\
\text { OPEEN } \\
\text { JOHNAL } \\
\text { SYSTEMS }\end{array}$ \\
\hline
\end{tabular}

\title{
PROPOSTA DE TRILHA INTERPRETATIVA NA SERRA DO MONTE MOR, ACOPIARA/CEARÁ: METODOLOGIA PARA O ENSINO DA GEOMORFOLOGIA
}

\author{
Mayra Alves Pinheiro ${ }^{1}$, Juliana Maria Oliveira Silva ${ }^{2}$ \\ ${ }^{1}$ Universidade Regional do Cariri - URCA Email: mayra.acops@hotmail.com \\ ${ }^{2}$ Professora da Universidade Regional do Cariri - URCA Email: juliana.oliveira@urca.br
}

Artigo recebido em 10/12/2017 e aceito em 09/03/2018

\begin{abstract}
RESUMO
O objetivo do estudo é propor uma trilha interpretativa com finalidade turística educacional, possibilitando a preservação e conservação da mesma, considerando uma abordagem geomorfológica. A proposta da trilha interpretativa na Serra do Monte Mor em Acopiara/Ce proporciona uma caminhada que vai desde a comunidade Monte Mor até o ponto mais alto da serra, perpassando, desse modo, por diversas paisagens e garantindo sensações distintas ao longo do caminho. A trilha foi dividida em 6 paradas tendo como base a análise da paisagem e grau de declividade e atitude. Ressaltamos a importância da interpretação da paisagem e conhecimento das formas do relevo como uma importante ferramenta da educação ambiental, visto que com ela se torna possível agregar novos valores ao visitante por meio de novas experiências e além da abordagem que pode ser trabalhada em sala de aula nas escolas de Acopiara, apresentação e elaboração de cartilha para melhor expor o conteúdo sobre a trilha.
\end{abstract}

Palavras-chave: Trilha interpretativas; Ensino; Geomorfologia.

\section{PROPOSAL FOR INTERPRETATIVE TRACK IN SERTE DO MONTE MOR, ACOPIARA / CEARÁ: METHODOLOGY FOR THE TEACHING OF GEOMORPHOLOGY}

\begin{abstract}
The objective of the study is to propose an interpretive trail with educational tourist purpose, allowing the preservation and conservation of the same, considering a geomorphological approach. The proposal of the interpretive trail in the Serra do Monte Mor in Acopiara / Ce provides a walk that goes from the Monte Mor community to the highest point of the mountain range, thus passing through several landscapes and guaranteeing different sensations along the way. The trail was divided into 6 stops based on the analysis of the landscape and degree of slope and attitude. We emphasize the importance of landscape interpretation and knowledge of relief forms as an important tool of environmental education, since with it it becomes possible to add new values to the visitor through new experiences and beyond the approach that can be worked in the classroom in schools of Acopiara, presentation and elaboration of booklet to better expose the content on the trail
\end{abstract}

Key-words: Track interpretative; Teaching; Geomorphology. 


\section{INTRODUÇÃO}

Nos últimos anos, alguns estudiosos têm se dedicado a discutir a importância das práticas de campo no processo de formação dos geógrafos e dos professores de Geografia. Nesse contexto, as viagens exploratórias com fins de observar e descrever fatos da paisagem assumiam tal papel, passando, depois, a ficar bastante associada à Geografia Tradicional marcada por um ensino puramente descritivo e por uma leitura não muito crítica e reflexiva do espaço geográfico - procedimentos ainda utilizados e difundidos em trabalhos de campo.

Na Atualidade, o trabalho de campo é um recurso metodológico de ensinoaprendizagem, que vem sendo; (re) valorizado e (re) discutido na Geografia como um dos instrumentos de maior interesse e produtividade no ensino dessa ciência, pois é o campo o local de onde se extraem as informações que possibilitam a construção das elaborações teóricas e onde a eficácia e a utilidade das formulações teóricas construídas são testadas (CAVALCANTI, 2007, p. 03). As trilhas e travessias são, geralmente, caminhos tradicionalmente conhecidos por diversas comunidades visando principalmente a locomoção. Com a apropriação desse conhecimento tradicional por outros segmentos sociais temos a popularização de várias trilhas objetivadas a aproximar o visitante ao ambiente natural ou conduzi-lo a uma determinada mensagem específica (FONTES e VITORINO, 2012).

Segundo Costa (2012), a utilização de trilhas ecológicas tem como finalidade aproveitar os momentos de lazer do visitante para a transmissão de conhecimentos, pois a compreensão dos processos e acontecimentos ali presentes se torna mais fácil através do contato com a paisagem, tanto do ponto de vista recreativo quanto educativo Cordeiro e Bastos (2014), apontam que o geoturismo no semiárido cearense pode ser reconhecido como um importante alternativo para a manutenção de famílias nos sertões secos. Visto que, trata-se de uma atividade capaz de exercer um papel positivo na diversificação e no desenvolvimento econômico dos sertões, no qual as atividades tradicionais como, por exemplo, a agricultura de subsistência e a pecuária extensiva se encontram em decadência. Além desses aspectos, o geoturismo também vem sendo apontado como um instrumento capaz de contribuir para o aumento da autoestima dessas famílias, justamente por estas obterem através dessa atividade, uma maior inserção social (CORDEIRO; BASTOS, 2014).

As aulas voltadas para o ensino à geomorfologia têm como objetivo principal estudar as formas de relevo encontradas no planeta, mas mesmo assim, ainda podemos encontrar barreiras, pois muitas vezes é repassada como conteúdo diluído e espaçado, fazendo com que o aluno não consiga perceber a disciplina no seu dia-a-dia, dentro de sua realidade. Neste tipo 
de contexto, passou-se a explicar o porquê da relação entre o conhecimento teórico e o da prática investigativa no campo e no laboratório. Justificava-se, assim, a importância da análise integrada, envolvendo os processos interativos para explicar as diferentes formas de relevo da superfície da Terra. (Silva et al, 2011). A relevância da pesquisa se justifica, ainda, pela ausência de discussões relevantes para a área de estudo e lacuna do reconhecimento do seu patrimônio natural de maneira geral, e desenvolver um roteiro para configurar uma trilha interpretativa de caráter autoguiada para suporte as práticas de ensino de geomorfologia e desenvolver o turismo local uma vez que suas potencialidades locais são propícias para fomentar discussões, entre moradores, também turistas e sociedade escolar. O objetivo do estudo é propor uma trilha interpretativa com finalidade turística educacional, gerando preservação e conservação da mesma, apresentando uma abordagem geomorfológica, de modo a maximizar a conscientização ambiental do visitante (alunos) e minimizar os impactos que podem ser gerados.

\section{MATERIAL E MÉTODOS}

\section{Área de estudo}

A área de estudo encontra-se nas proximidades da Zona de Cisalhamento de Senador Pompeu e de outras zonas de cisalhamento menores, transcorrentes, contracional, dextral e sinistral, fato que pode ter condicionado o controle estrutural dessas elevações, com o clima Tropical Quente Semiárido, apresentando uma média pluviométrica de 748,5 com inserida na Depressões Sertanejas e com presença de Maciços Residuais, o tipo de solo que mais predomina no município de Acopiara é o Solos Aluviais, Solos Litólicos, Planossolo Solódico, Podzólico Vermelho-Amarelo e Vertissolos com vegetação de Caatinga Arbustiva Densa, Floresta Caducifólia Espinhosa e Floresta Subperenifólia Tropical Pluvial (IPECE, 2015).

Complementando o quadro natural básico, importante para a análise proposta aqui, o município de Acopiara é drenado por diversos pequenos riachos sazonais, em sua maioria, os quais possuem vazão relacionada ao período chuvoso. Por fim, a área de estudo se configura como uma região divisora de águas de sub-bacias hidrográficas do Alto Jaguaribe. A trilha proposta está situada em dois municípios vizinhos Acopiara e Piquet Carneiro, pertencendo a microrregião do Sertão de Senador Pompeu, sendo uma das Microrregiões do Estado do Ceará pertencente à mesorregião Sertões Cearenses, divisão esta que tem como objetivo 
central um planejamento regional do Ceará, gerenciada pelo Instituto de Pesquisa e Estratégia Econômica do Ceará - IPECE (Figura 1).

Figura 1: Mapa do Modelo Digital de Elevação da Trilha do Monte Mor. Perfil Topográfico da Trilha.
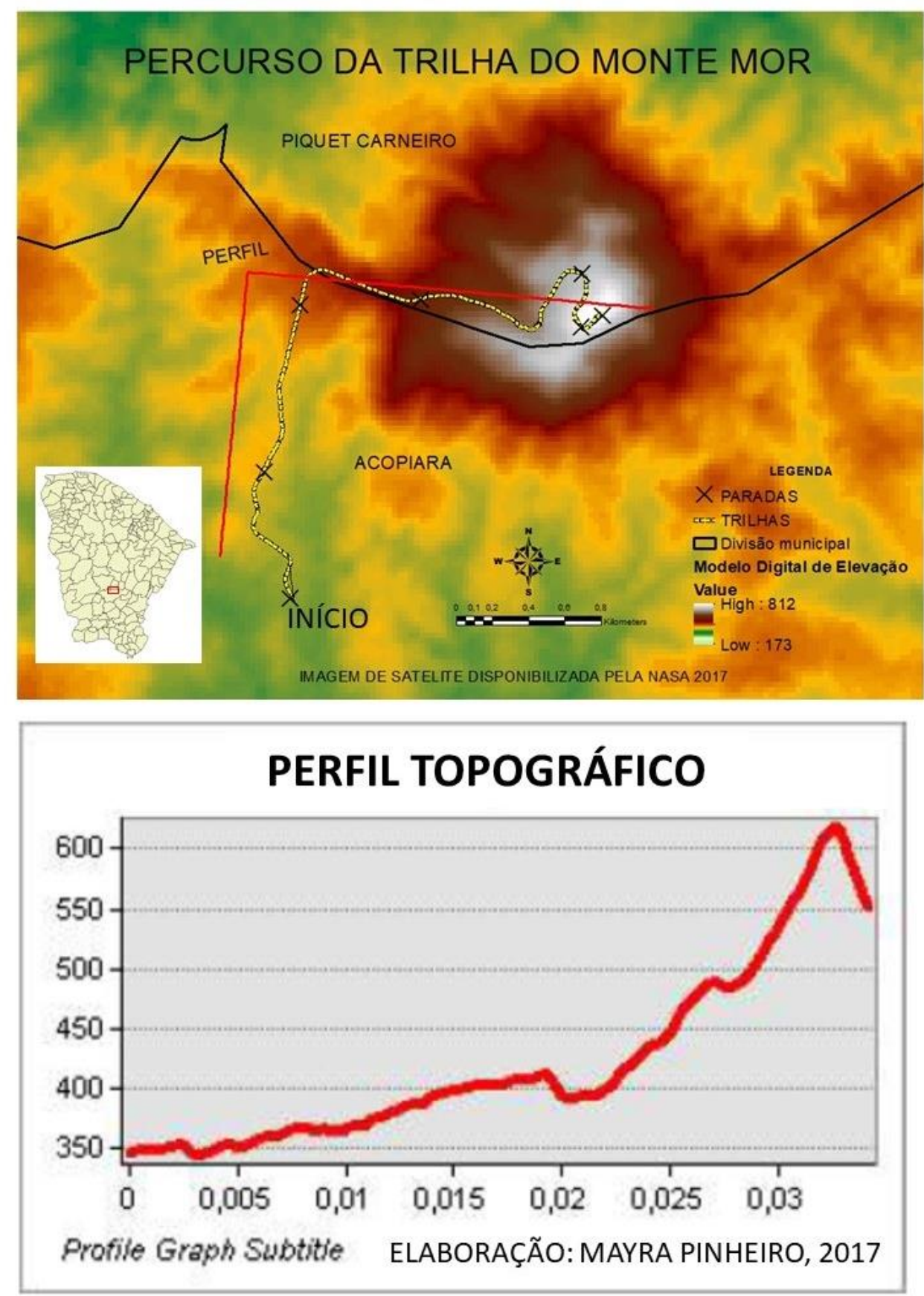
As atividades realizadas na referida área, sendo definida como um do principal espaço das aulas de campo no município, a trilha em questão fica aproximadamente $11 \mathrm{~km}$ de distância da sede da cidade de Acopiara, cidade está que tem o acesso mais fácil e rápido para a trilha. Este percurso já vem sendo utilizado por aventureiros da região e também por religiosos que uma determinada época do ano fazem uma peregrinação até o topo da trilha, com o intuído de devoção e tradição local.

\section{Procedimentos técnicos}

A construção desse trabalho foi dividida em quatro etapas: $1^{\text {a }}$ levantamento bibliográfico sobre proposta de trilha, aspectos geomorfológicos e ensino de geomorfologia, $2^{\mathrm{a}}$ pesquisa sobre a Serra do Monte Mor e o seu entorno, $3^{\mathrm{a}}$ visita a área de estudo e, por fim, $4^{\mathrm{a}}$ a elaboração da trilha interpretativa com a finalidade de práticas de campo para o ensino de geomorfologia.

Em uma primeira etapa e preliminar, realizamos um estudo a partir de referências acadêmicas sobre, temática de ensino de geomorfologia e trilhas interpretativas, para que fosse possível pensar em uma trilha interpretativa na área da Serra do Monte Mor e a comunidade nela ali inserida. Tal pesquisa foi subsidiada em um segundo momento pelo pré e pós-campo ao realizar o levantamento de informações, mapas e fotos de satélite sobre a Serra do Monte Mor e sua comunidade, a fim de conhecer melhor a região para a visita de campo e para a realização deste trabalho.

$\mathrm{Na}$ terceira etapa realizou-se uma visita a área a comunidade do Monte Mor e percorreu-se a trilha já utilizada pela população local e por aventureiros. Nas paradas foram marcados pontos com GPS que potencialmente poderiam se configurar em pontos estratégicos da trilha interpretativa, para auxiliar na elaboração da trilha.

Por fim, a última etapa do trabalho significou a elaboração da trilha interpretativa e na produção do presente trabalho. A produção cartográfica foi elaborada pelo Software ArcGis 10.3, Datum Sirgas 2000/ UTM Zona 24S, do Laboratório de Geomorfologia e Pedologia - GEOPED e Google Earth para marcação da trilha. Também foram levantadas curiosidade variadas sobre o local que pudessem despertar a atenção e o interesse do público. 


\section{RESULTADOS E DISCUSSÕES}

As utilizações das trilhas ocorrem não somente objetivando a transmissão de conhecimentos, mas também propiciando atividades que analisam os significados dos eventos observados no ambiente bem como as características do mesmo (SANTOS et al 2011). As trilhas servem, ainda, como caminho aos atrativos ecoturísticos, além de serem utilizadas pelas populações residentes a fim de atenderem suas necessidades de deslocamentos para realizar atividades de subsistência, tais como ligação entre sítios de agricultura e as residências, etc. Essa diversidade de usos é fator relevante, seja para o visitante (ecoturista), seja para a população residente, já que a perpetuação do traçado em trilha é assegurada na prática das ações sobre ela (CASTRO, 2004).

Dentro do turismo, há diversos segmentos que apresentam vocação para implementação em diferentes contextos urbanos e rurais dos municípios. No caso específico de municípios situados fora da faixa litorânea e costeira, vêm sendo desenvolvidas atividades associada ao chamado turismo sustentável, como o ecoturismo, o turismo de aventura, o turismo rural, o turismo comunitário e o geoturismo (VIANA; NASCIMENTO, 2009). De acordo com Vasconcellos (1997 apud SANTOS et al 2011) as trilhas interpretativas tem sido um dos instrumentos pedagógicos de interpretação ambiental mais utilizados tanto em ambientes naturais como em construídos.

Assim, a trilha interpretativa também passa a exercer a função de acrescentar valor a experiência do visitante, através do oferecimento de informações sobre as características históricas, culturais e ambientais do lugar (MURTA E GOODEY, 2002). Recursos este que pode ser utilizado no ensino de geografia em relação ao ensino específico da geomorfologia, visto que esta possui grande importância na compreensão dos fenômenos naturais e na evolução da paisagem, uma vez que estes podem funcionar como facilitadores do ensinoaprendizagem, tornando os conteúdos ensinados mais significativos na reflexão dos alunos.

A geomorfologia possui conteúdos presentes no cotidiano de todas as sociedades (TORRES e SANTANA, 2009), estabelecendo relações com vários outros ramos da ciência geográfica, contudo, exige uma grande capacidade de abstração muitas vezes não efetivada pelos alunos. Verifica-se a necessidade de haver uma complementação para estes conteúdos, principalmente com utilização de instrumentos didáticos diferenciados. 


\section{Proposta de trilha interpretativa}

A proposta da trilha interpretativa na Serra do Monte Mor proporciona uma caminhada que vai da comunidade Monte Mor até o ponto mais alto da serra, perpassando, desse modo, por diversas paisagens e garantindo sensações distintas ao longo do caminho, percurso este que pode ser realizado de transporte que pode facilitar o acesso para criança e idosos.

A comunidade se encontra na zonal rural do município de Acopiara, para objetivar o trabalho a trilha foi dividia em 6 paradas tendo como base a análise da paisagem e grau de declividade e atitude do terreno. Inicia-se a trilha a uma elevação de 349 metros de altitude, em meio a uma vegetação de Caatinga, onde, à medida que a trilha é percorrida, é facilmente perceptível as mudanças na vegetação, se sabe, o relevo e o clima influenciam diretamente no tipo de vegetação de uma determinada área, desta forma, nas porções mais altas da área de estudo, verificáveis acima, por receberem mais umidade, principalmente nos setores próximos ao topo, a vegetação é mais densa, caracterizando a ocorrência da mata seca, a Floresta Subcaducifólia Tropical Pluvial, de porte predominantemente arbóreo. Em contato com esta formação, ocorrem na área também mais duas espécies vegetacionais, a Caatinga Arbórea Floresta Caducifólia Espinhosa e a Caatinga Arbustiva. (CARMO, et al 2009) (Figura 2)

- Distância a ser percorrida: 4.25 km;

- $\quad$ Altitude máxima: 613 metros;

- Grau de dificuldade: Mediano, em decorrência da alta declividade;

- Tempo aproximado para conclusão da atividade: 2h 30 minutos. 
Figura 2: Mapa do percurso da Trilha Interpretativa do Monte Mor

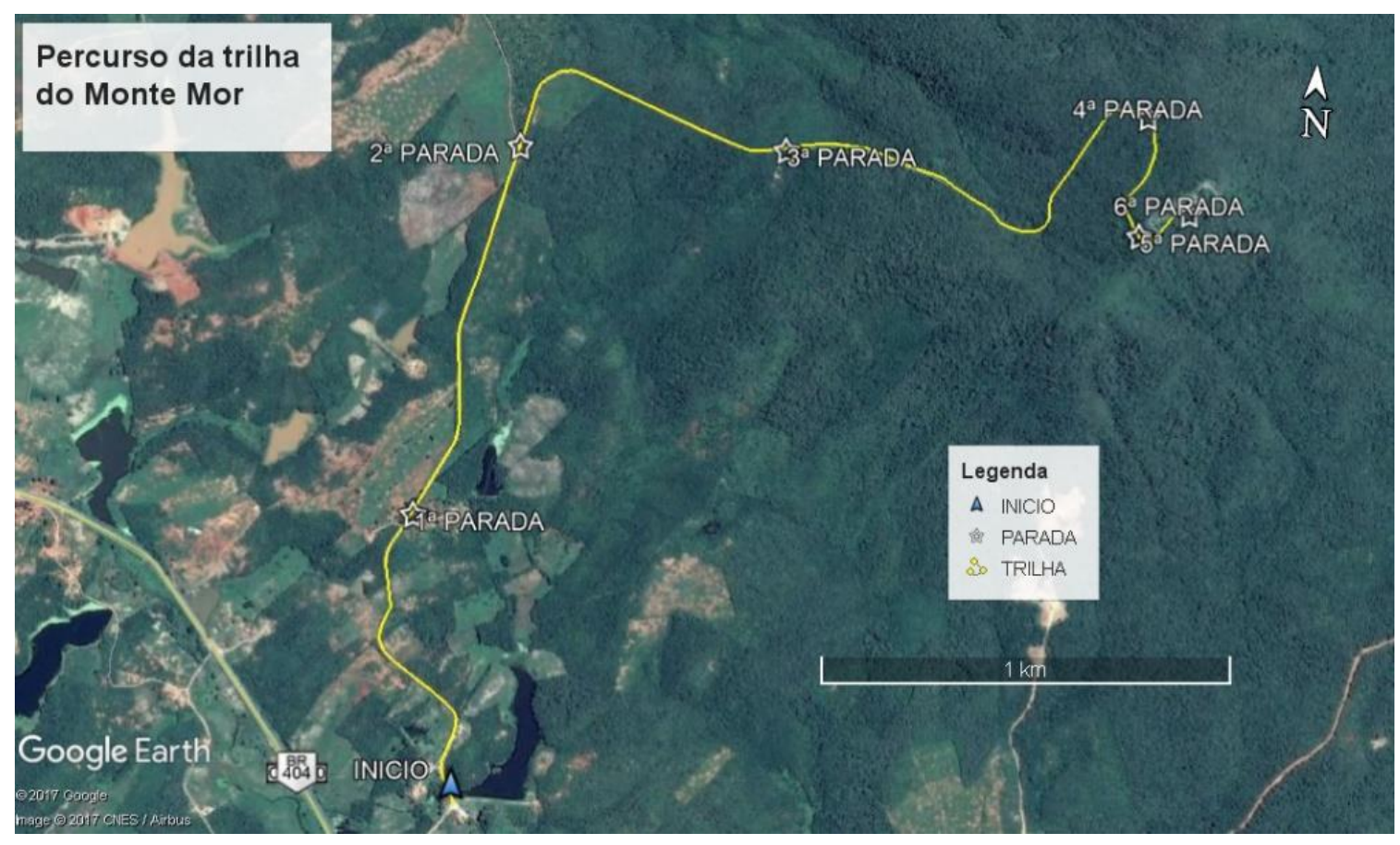

Fonte: Google Earth, 2017

O início da trilha proposta localiza-se na comunidade do Monte Mor, próximo a um açude. Nesse ponto pretende-se que seja criado um painel com informações gerais sobre a região, orientações sobre a trilha como sua extensão, dificuldade e tempo estimado. No marco inicial da trilha propõe-se a distribuição de folders didáticos com ilustrações da área e informaçõessobre o percurso da trilha, assim como as orientações de cada ponto de parada, explicando os níveis de dificuldade ealtitude de cada parada. (Figura 3) 
Figura 3: Perfil topográfico da trilha apresentando as paradas.

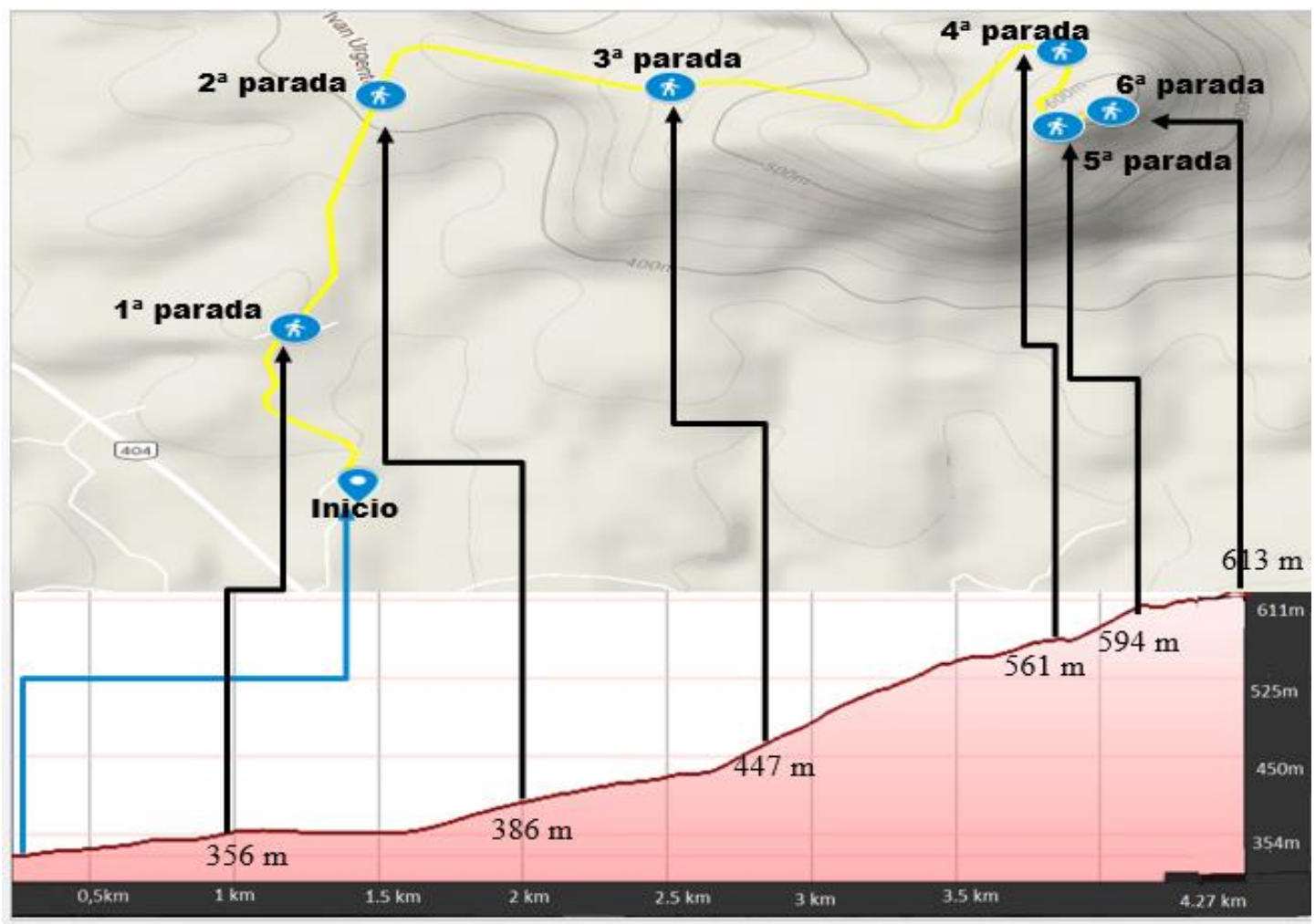

\section{I $^{a}$ PARADA (Vista para o topo da trilha)}

Nesse ponto, com o auxílio do folder, pretende-se tratar da formação da paisagem e fazer uma discussão da caracterização ambiental da região abordando conteúdo que são vistos em sala de aula.

\section{$2^{a}$ PARADA (Mirante da serra)}

$\mathrm{Na}$ segunda parada com altitude de 386 metros, predomínio de declividade suave ondulada a ondulada variando de 5 a 17\%. No Mirante das Serras é possível ver a Serra do Maia. Este Maciço Residual tem $22 \mathrm{~km}$ de extensão e com ponto de elevação que chega aos 720 metros. Evidenciará no folder a importância de se preservar estas unidades de paisagem, por serem áreas de recarga hídrica e que quando degradadas pelo homem, ficam mais propícias a ações erosivas e a formações de voçorocas, prejudicando o solo, relevo e os componentes bióticos (Figura 4). 
Figura 4: Mirante da Serra do Maia. Fonte: Ezia Sousa, 2017

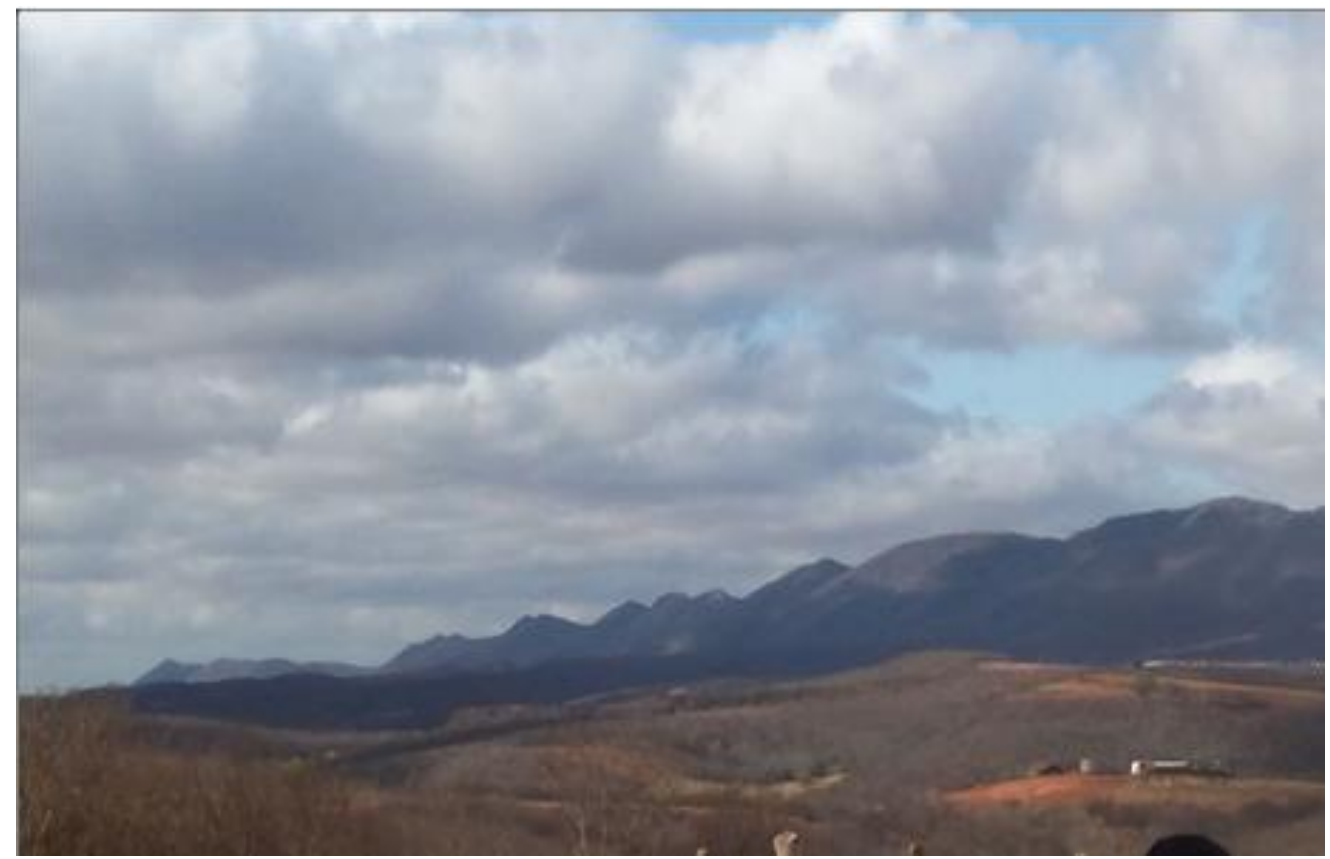

\section{$3^{a}$ PARADA (Contação de hitorias locais)}

Nesse ponto com altitude de 447 metros, predomínio de declividade plana variando de 0-3\% . Aqui propõe-se abordar uma breve informação sobre os motivos da população das cidades vizinhas escolhe o local para práticas esportivas, onde os moradores se dirigem a trilha, e também fazer um levantamento das tradições locais. (Figura 5)

Figura 5: Percuso da trilha mais plano. Fonte: Ezia Sousa 2017

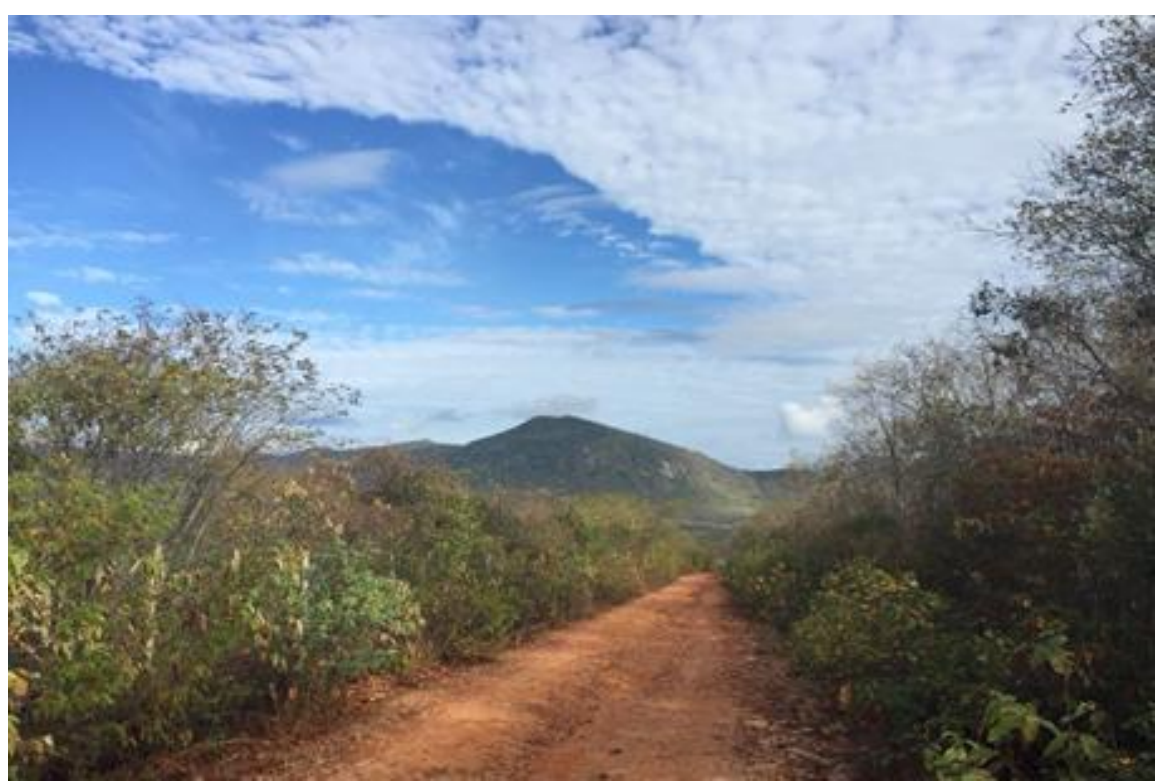




\section{$4^{a}$ PARADA (Trilha fechada)}

Chegando na quarta parada numa altitude de 561 metros, predomínio de declividade forte ondulada variando de $20-32 \%$. Aqui pretende informar ao visitantes e alunos sobre o período que foi construído a estrada de pedra, com o intuído de facilitar o acesso para carros que levavam material para construção e instalação das antenas de telefonia e energias. Com isso apresentando os tipos de uso que o homem pode fazer na natureza. (Figura 6)

Figura 6: Trilha cm vegetação fechada. Fonte: Ezia Sousa 2017

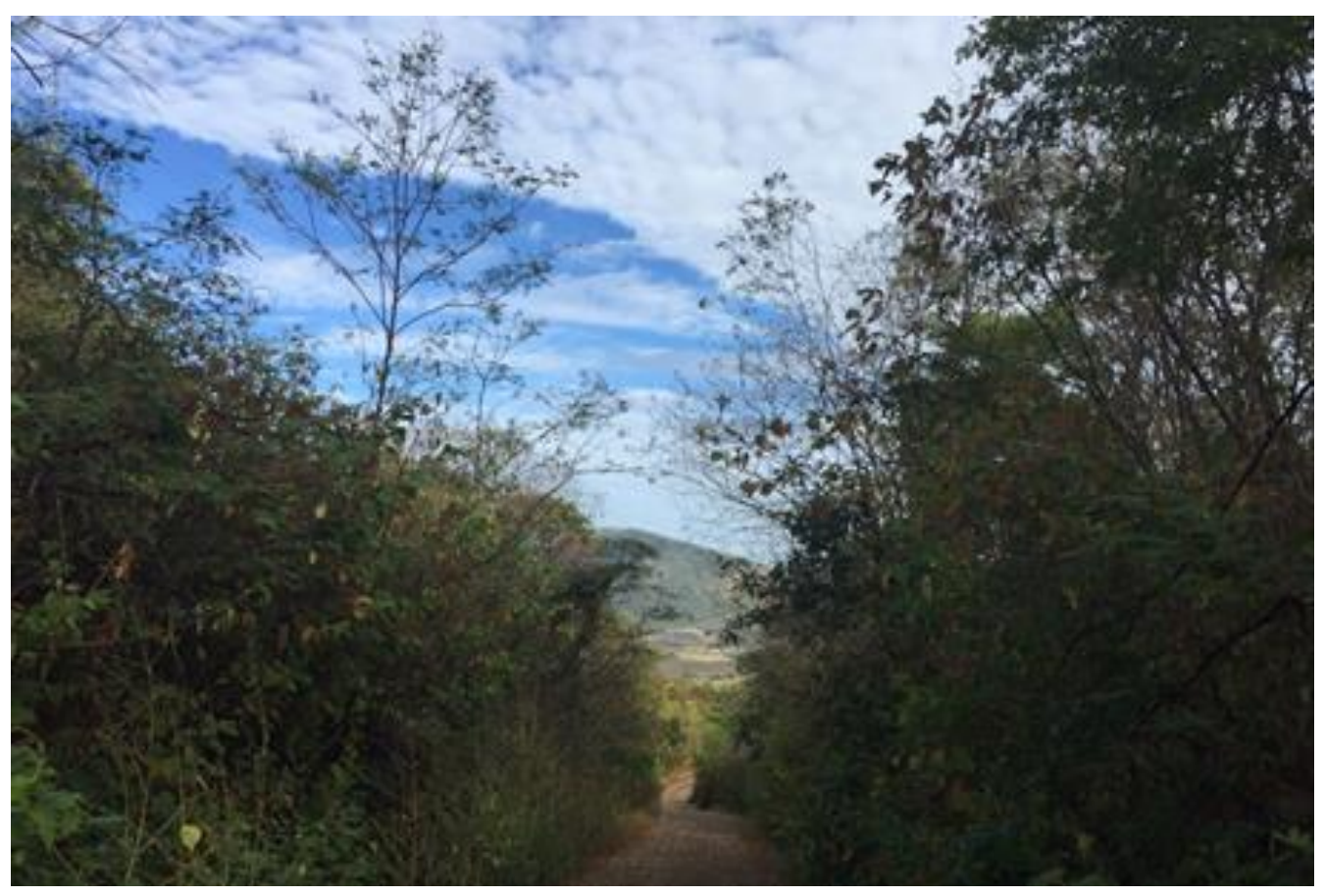

\section{$5^{a}$ PARADA (Mirante para as serras)}

Numa altitude de 594 metros, predomínio de declividade forte ondulado a montanhoso variando de 29 - 49\% Nesse ponto pode-se apresentar um discursão sobre a dinâmica ambiental da região, com efeito, a formação das rochas que sustentam as serras podendo observar o nível de declividade da área a formação do relevo. (Figura 7) 
Figura 7: Mirante para cojunto de serras. Fonte: Ezia Sousa 2017

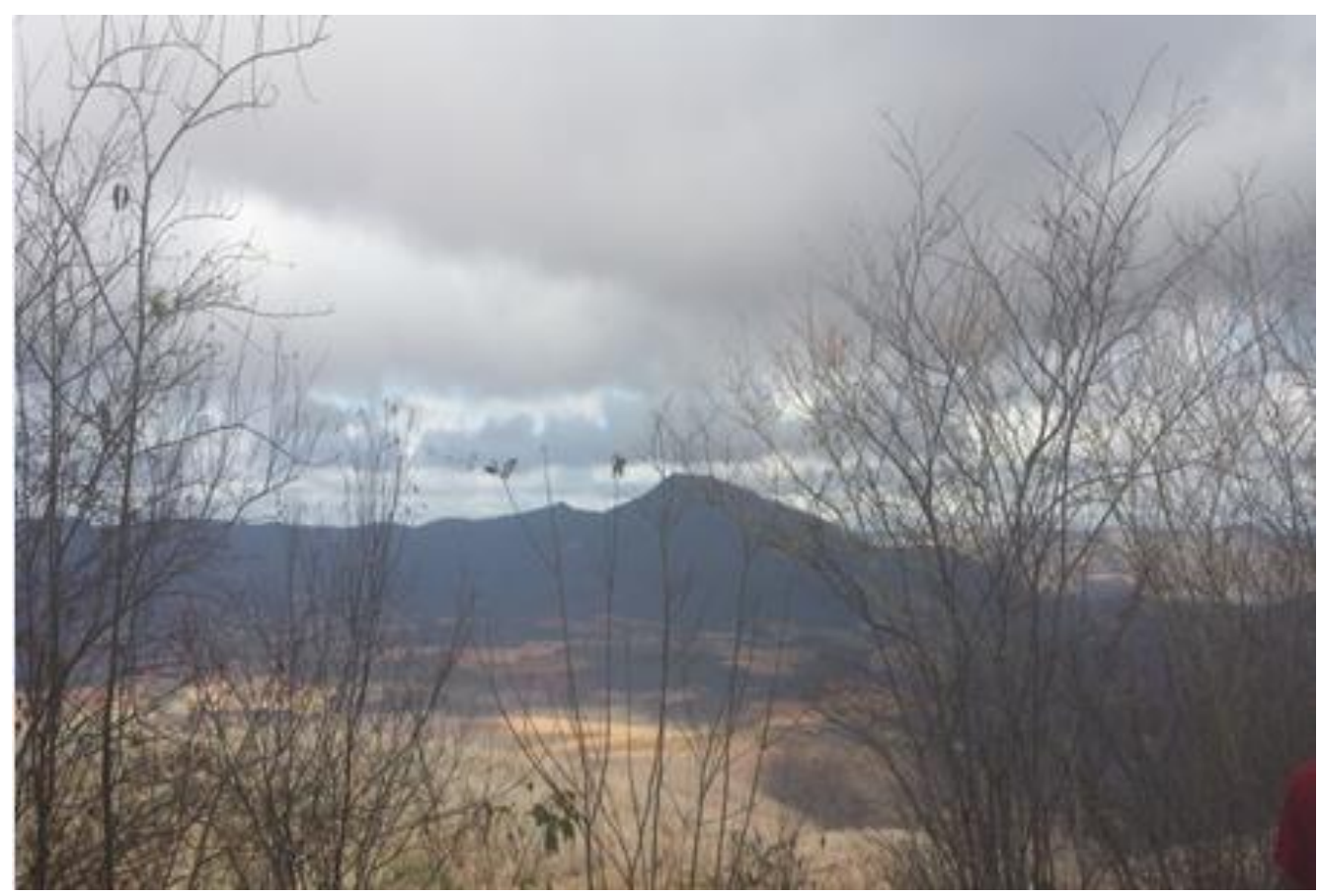

\section{PARADA (Final da trilha)}

Nesse ponto com altitude de 613 metros, predomínio de declividade forte ondulado a montanhoso variando $34-57 \%$ O visitante e alunos ao chegar no final da trilha, se depara com a vista proporcionada pelo mirante e tem uma visão geral da comunidade do entorno da Serra do Monte Mor e sede urbana de Acopiara, construindo um importante ponto de reflexão. Deste modo, convida-se visitantes a refletirem sobre todos os pontos de parada e sobre as distintas paisagens avistadas, a formação do relevo, processos e formas. Assim, pretende-se que todos possam refletir sobre as formações das paisagens e os impactos positivos e negativos da atividade humana no meio ambiente. (Figura 8) 
Figura 8: Vista a partir do ponto mais alto da trilha. Fonte: Ezia Sousa, 2017.

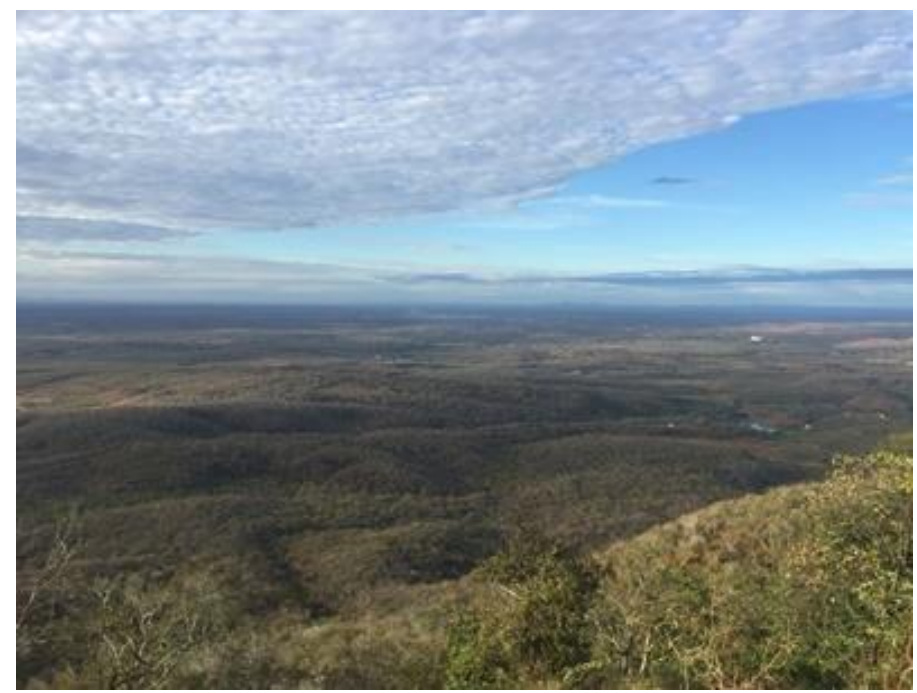

\section{Propostas de intervenções na trilha}

Se faz importante a introdução de pequenos mastros de madeira, com as pontas pintadas de amarelo, ao longo da trilha a fim de indicar o caminho; com a finalidade de proporcionar uma melhor interação com a trilha, propõe a introdução de placas sinalizadoras indicando a direção da trilha, prioritariamente nos pontos 02, 03, 04, uma vez que se localizam perto de outros pontos que não está no percurso da trilha e se fazem necessário para a localização da trilha. Para garantir uma maior acessibilidade, propomos a implementação de áreas de descanso, contendo um pequeno quiosque com bancos para repouso no ponto 04 e ao final da trilha, no ponto 06 .

\section{CONSIDERAÇÕES FINAIS}

Podemos concluir que a prática de campo é uma atividade de significativo valor didático e pedagógico, no processo ensino-aprendizagem de Geografia, uma vez que possibilita ao aluno um contato direto com a paisagem geográfica. Nesse sentido, planejou-se uma introdução de uma trilha interpretativa, subsidiada, principalmente, pela caracterização geral da área de estudo. Assim, pretende-se com a trilha interpretativa na Serra do Monte Mor não só garantir uma experiência diferente, mas sim agregar valor a vivência do visitante, já que é possível introduzi-los em um novo contexto histórico, cultural e econômico, incorporando também novos valores ambientais.

Desse modo, ressaltamos a importância da interpretação da paisagem e conhecimento das formas do relevo como uma importante ferramenta da educação ambiental, 
visto que com ela se torna possível agregar novos valores ao visitante por meio de novas experiências e além da abordagem que pode ser trabalhada em sala de aula nas escolas de Acopiara, apresentação e elaboração de cartilha para melhor expor o conteúdo sobre a trilha. Por fim, observa-se que as trilhas interpretativas, de maneira geral, representam um importante instrumento para a mitigação dos impactos ocasionados pelo ser humano, além de ser uma área pouco conhecida cientificamente e com a divulgação da trilha possa ganhar espaço diante da academia e dos gestores municipais uma vez que apresenta um grande potencial para conservação ambiental.

\section{REFERÊNCIAS}

ALMEIDA, D. A.; PARENTE JÚNIOR, W. C.; BESSERA NETA, N. C.; COSTA, M. L. Erosividade do solo e erosividade da chuva na Serra do Tepequém - Roraima. Revista Acta Geográfica, v.3, n.6, p.39-46, 2009.

CABRAL, J. B. P.; BECEGATO, V. A.; SCOPEL, I.; LOPES, R.M. Estudo da erosividade e espacialização dos dados com técnicas de geoprocessamento na carta topográfica de Morrinhos - Goiás/Brasil para o período de 1971 a 2000. GEOFocus, n.5, p.1 - 18, 2005.

CEPAGRI. Clima dos municípios paulistas, 2018. Disponível em: <http://www.cpa.unicamp.br/outras-informacoes/clima_muni_224.html >. Acesso em: $20 \mathrm{de}$ março de 2018.

IBGE. Instituto de Geografia e Estatística. Divisão territorial brasileiro e limites territoriais:

IBGE cidades - São Carlos, 2018. Disponível em: <

http://www.ibge.gov.br/cidadesat/painel/painel.php?codmun=351930\# >. 20 de março de 2018.

IBGE. Instituto de Geografia e Estatística. Manual Técnico de Uso da Terra $3^{a}$ Edição, 2013. Disponível em: <

http://www.ibge.gov.br/home/geociencias/recursosnaturais/usodaterra/manual_usodaterra.sht $\underline{\mathrm{m}}>$. Acesso em: 31 de maio de 2017.

IGC. Instituto Geográfico e Cartográfico. Região administrativa Central, 2018. Disponível em: < http://www.igc.sp.gov.br/>. Acesso em: 20 de março de 2018.

INMET. Instituto Nacional de Mereologia. Banco de Dados Meteorológicos para Ensino e

Pesquisa, 2017. Disponível em < http://www.inmet.gov.br/projetos/rede/pesquisa/ $>$ Acesso em 27 de janeiro de 2017.

JANSSON, M. B. Land erosion by water in different climates. Department of Physical 
Geography, Upsala University. UNGI Rapport n.57, 1982, 151p.

JUNIOR, R. F. V. Diagnóstico De Áreas De Risco De Erosão E Conflito De Uso Dos Solos Na Bacia Do Rio Uberaba, 223f, 2008. Tese (Doutorado em Ciências Agrárias). Universidade Estadual Paulista, 2008.

KOTTERK, M.; GRIESER, J.; BECK, C.; RUDOLF, B.; RUBEL, F. World Map of the Köppen-Geiger climate classification updated. Meteorologische Zeitschrift, v.15, n.3, p.259263, 2006.

OCDE. Organização para a Cooperação e Desenvolvimento Econômico: Rumo ao desenvolvimento sustentável. Indicadores ambientais. Governo do estado da Bahia. Secretaria de Planejamento. Ciência e Tecnologia, 2002, 244p.

OLIVEIRA, C. H.; SANTOS, J. E.; TOPPA, R. H. Efeitos do uso do solo urbano na qualidade ambiental e de vida, na vegetação e na impermeabilização do solo. IN: SANTOS, J. E.; CAVAlheiro, F. PIRES, J. S. R.; OliVEIRA, C. H. PIRES, A. M. Z. C. R. (Org.). Faces da Polissemia da Paisagem. 1a ed. v. 2, São Carlos, Rima, p.585-619, 2004.

PARYSOW, P.; WANG, G.; GERTHER, G. Z.; ANDERSON, A. B. Assessing uncertainly of erodibility factor in national cooperative soil surveys, a case study at Fort Hood. Texas. J Soil Water Conserv, v.56, p.56:207, 2001.

PINATTI, J. M.; MOSCHINI, L. E.; DOS SANTOS, R. M.; TREVISAN, D. P. Dinâmica da Paisagem da Zona de Amortecimento do Parque Estadual do Vassununga, SP. IN: José Eduardo dos Santos; Elisabete Maria Zanin. (Org.). Faces da Polissemia da Paisagem. 1ed. São Carlos, SP: Rima, 2013, v.5, p.144-162.

RIBEIRO, F. L.; CAMPOS, S.; PIROLI, E. L; SANTOS, T. G.; CARDOSO, L. G. Uso da terra do Alto rio pardo, obtido a partir da análise visual in: Anais. I Ciclo de Atualização Florestal do Conesul Santa Maria: UFSM, 1999. v. único, p.75 - 81, 1999.

RITTERS, K. H.; O’NEIL, R. V.; HUNSAKER, C. T.; WICKHAM, J. D.; YANKEE, D. H. TIMMINS, S. P. A factor analysis of landscape pattern and structure metrics. Landscape Ecology, v.10, n.1, p.23-39, 1995.

ROSS, J. L. S. Análise empírica da fragilidade dos ambientes naturais e antropizados. Revista do Departamento de Geografia/FFLCH/USP, n.8, p.63-73, 1994.

SANTOS, A. F. Morfometria da microbacia hidrográfica do Ribeirão Faxinal BotucatuSP e alterações em suas áreas de biomassa no período de 1972 a 2000.70 f. Dissertação (Mestrado em Agronomia) - Faculdade de Ciências Agronômicas. Universidade Estadual Paulista Julio de Mesquita Filho, Botucatu, 2004. 
SANTOS, A. G. Viabilidade técnica e socioeconômica dos sistemas agroflorestais utilizados por agricultores familiares em Roraima. Dissertação (Mestrado em Ciências Econômicas) - UFRGS, Universidade Federal do Rio Grande do Sul, Porto Alegre, 2009.

SANTOS, G. G.; GRIEBELER, N. P.; OLIVEIRA, L. F. C. Chuvas intensas relacionadas à erosão hídrica. Revista Brasileira de Engenharia Agrícola e Ambiental, v.14, n.2, p. 115$123,2010$.

SEADE. Fundação Sistema Estadual de Análise de dados. Perfis municipais, 2018. Disponível em: < http://www.seade.gov.br/produtos/perfil/perfil.php>. Acesso em: 20 de março de 2018.

SOARES FILHO, B. S.; CARMO, V. A.; NOGUEIRA, W. J. Metodologia de elaboração da carta do potencial Erosivo da bacia do rio das velhas (mg). Revista Geonomos, v. 6, n. 2, p.45-54, 1998 .

STEFFEN, W.; SANDERSON, A.; TYSON, P. D.; JÄGER, J.; MATSON, P. A.; MOORE III, B.; OLDFIELD, F.; RICHARDSON, K.; SCHELLNHUBER, H. J.; TURNER, B. L.; WASSON, R. J. Global change and the earth system: A planet under pressure, SpringerVerlag Berlin Heidelberg, New York, 2004, 336 p.

TEIXEIRA, M. A.; MAGALHÃES, P. S. G.; BRAUNBECK, O. A. Equipamento para extração de amostras indeformadas de solo. Revista Brasileira de Ciência do Solo, v. 24, n.4, p.693-699, 2000.

TONELLO, K. C. Análise hidroambiental da bacia hidrográfica da Cachoeira das Pombas, Guanhães, MG. Viçosa: Universidade Federal de Viçosa, 2005, 85 p

TREVISAN, D. P.; MOSCHINI, L. E. . Determinação da Fragilidade Ambiental do município de São Carlos, São Paulo, Brasil. Geografia Ensino \& Pesquisa, v.20, p.159-167, 2016.

TREVISAN, D. P.; MOSCHINI, L. E. . Dinâmica de Uso e Cobertura da Terra em Paisagem no Interior do Estado de São Paulo: Subsídios para o planejamento. Fronteiras: journal of social, technological and environmental science, v.4, p.16-30, 2015.

VALENTIN, C.; POESEN, J.; YONG LI. Gully erosion: Impacts, factors and control. Catena, v.63, p.132-153, 2005.

WANG, G.; GERTNER, G. Z.; LIU, X.; ANDERSON, A. B. Uncertainly assessment of soil erodibility factor for revised universal soil loss equation. Catena, v.24, p.1-14, 2001.

WISCHMEIER, W.H. \& SMITH, D.D. Predicting rainfall erosion losses: a guide to conservation planning. Washington, United States Department of Agriculture, 1978, 58.p 